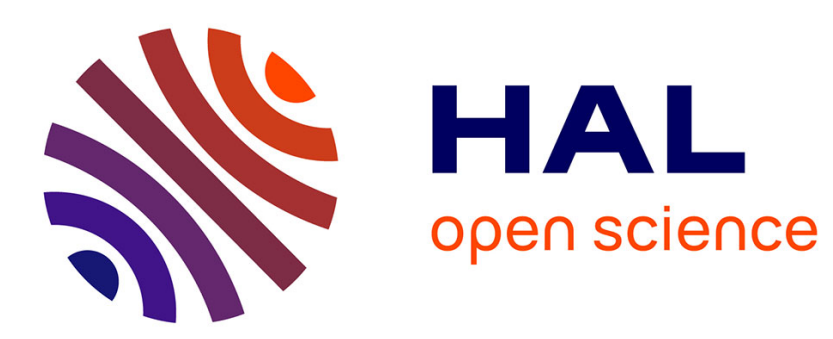

\title{
Modelling of filtration: from the polarised layer to deposit formation and compaction
}

\author{
Patrice Bacchin, Martine Meireles, Pierre Aimar
}

\section{To cite this version:}

Patrice Bacchin, Martine Meireles, Pierre Aimar. Modelling of filtration: from the polarised layer to deposit formation and compaction. Desalination, 2002, 145, pp.139-146. 10.1016/S00119164(02)00399-5 . hal-00201115

\section{HAL Id: hal-00201115 \\ https://hal.science/hal-00201115}

Submitted on 23 Dec 2007

HAL is a multi-disciplinary open access archive for the deposit and dissemination of scientific research documents, whether they are published or not. The documents may come from teaching and research institutions in France or abroad, or from public or private research centers.
L'archive ouverte pluridisciplinaire HAL, est destinée au dépôt et à la diffusion de documents scientifiques de niveau recherche, publiés ou non, émanant des établissements d'enseignement et de recherche français ou étrangers, des laboratoires publics ou privés. 
Modelling of filtration: From the polarised layer to deposit formation and compaction

\author{
P. Bacchin, M. Meireles and P. Aimar \\ Laboratoire de Génie Chimique UMR 5503, Université Paul Sabatier \\ 118 route de Narbonne, 31062 Toulouse Cedex 4, France \\ Tel : +33-5-6155-8163; Fax : +33-5-6155-6139 \\ bacchin@chimie.ups-tlse.fr, meireles@chimie.ups-tlse.fr, aimar@chimie.ups-tlse.fr
}

A theoretical study is developed for the modelling of mass accumulation from the polarised layer to the formation of a deposit. Concentrated suspension properties are accounted for through a solid pressure corresponding to osmotic pressure in the suspension and to compression resistance in the deposit. Mass and solvent transfer are depicted through balanced permeation/diffusion transport in the polarised layer and balanced friction/compaction forces in the deposit. The modelling applied to transient state for dead end filtration gives information about the coupling between mass transfer in the polarised layer and in the deposit. Consequences on specific cake resistance are presented and discussed.

Keywords: modelling, ultrafiltration, fouling, membrane, colloids, osmotic pressure

\title{
Introduction
}

Ultrafiltration, a membrane process now developed in a wide range of applications, can be severely limited by accumulation of matter on or in the membrane. This limitation is often interpreted either through mass polarisation (and a reversible back osmotic pressure) which is a rather good assertion for small solutes or though mass deposit formation (and the occurrence of an additional irreversible hydraulic resistance) mostly appropriate for particles. Most recent modelling developed for mass polarisation emphasise the importance of surface interaction both in cross flow filtration $[1,2]$ and in dead end filtration [3] while for deposit formation, cake compaction has also been depicted [4,5]. However for a colloidal suspension (macromolecule and small particles whose sizes are inferior to one micrometer), the deposit is directly the consequence of mass polarisation [6] and modelling of mass accumulation should account for both phenomena and their physical coupling. As reduction of irreversible fouling of membranes is an important factor in the optimisation and process operation, we have to rely on realistic modelling of such phenomena. With this in mind, a model accounting for properties of concentrated colloidal matter is here developed and applied to the description of transient dead-end filtration from polarised layer to deposit formation and compaction.

\section{Continuous description of colloidal properties}

Colloidal suspensions show complex behaviour when concentrated. For a stable suspension (global repulsive interaction between suspended matter) at equilibrium, a phase diagram (fig. 1) presents the different phases encountered when increasing the volume fraction:

- A "gas" phase where transport phenomena is mainly Brownian diffusion

- A "glass" phase where particles are interacting by repulsion with each other. These repulsive interactions induce a gradient (or collective) diffusion coefficient and the appearance of an order in the suspension.

- A solid phase when particles are so concentrated and so close that attraction occurs leading to the aggregation of particles.

Two transitions border these phases [7]: an order/disorder transition between gas and glass phases and a stable/unstable transition also called spinodal decomposition between glass phase (stable) and solid phase (unstable).

For a filtration process, two parameters can be relevant to describe the properties of colloidal suspension their variations within the polarised layer: the hydrodynamic coefficient, $K(\phi)$, (related to dynamic interaction between the solid and the liquid) and the solid pressure of the suspension, $\pi(\phi)$ (property of the medium at equilibrium). Solid pressure is used in this work to describe both osmotic pressure of the suspension and the compression pressure of a deposit (after the stable/unstable transition). These parameters change in a continuous way in the polarised layer (from the bulk to the 
close packed deposit) allowing to depict both "gas", "glass" and solid phase that exists during colloidal concentration. Variations of these parameters are here calculated according to a procedure already used in a previous work [6] for the data in table 1. For the calculation of compression pressure not included in the preceding work, calculations are made with the following relationship:

$$
\pi=\pi_{c r i t}\left(\frac{1-\frac{\phi_{c r i t}}{\phi_{c p}}}{1-\frac{\phi}{\phi_{c p}}}\right)^{1 / m}
$$

This power law relationship, a classical form for compressive yield stress expression [8], allows to describe the solid pressure continuously (critical osmotic pressure for critical volume fraction) and to have an infinite limit for close packed volume fraction (physically due to Born repulsion). The exponent, $\mathrm{m}$, in this relation corresponds to the compressibility of the deposit: a small value of $\mathrm{m}$ corresponds to a small compressibility: the solid pressure (related to the compression) increasing rapidly with volume fraction. This compressibility can integrate physical properties of particles such as roughness, "deformability”, stickiness (degree of VDW attraction, presence of chemical bond).

Evolution of solid pressure (fig. 2) with volume fraction illustrates transitions between phases existing in a concentrated colloid suspension (fig. 1). The transition between disorder and order suspension for a network of repulsive interacting particles is seen around 0.1 in volume fraction as an inflexion of solid pressure curve, better seen in log co-ordinates (inserted figure in fig. 2). The transition between the stable and unstable suspension (spinodal decomposition) (respectively black square and dashed line in fig.2) is described by a maximum in osmotic pressure [7] around 0.6 in volume fraction. After this transition, the osmotic pressure is plotted as a dashed line as this property cannot describe properties of an unstable suspension. After this transition, particles in the primary minimum of energy potential in DLVO theory are very close. The compressive pressure (open circle in fig. 2 from eq. 1) is then used to describe the pressure on the solid resulting from the friction between solid and liquid phases.

The evolution of solid pressure with volume fraction, as described by equation 1 , is a key point as it features the transition between phases responsible for the appearance of a deposit on a membrane $[9,10]$. It is interesting to note that these properties $K(\phi)$ and $\pi(\phi)$ are experimentally accessible respectively by settling velocity and osmotic stress or pressure filtration.

\section{Modelling}

\section{Mass transfer: Analogy between permeation in a deposit and diffusion in a polarised layer}

When accumulated at the membrane surface, the colloids are submitted to an irremediable (as it is the separation force) drag force due to permeation. At steady state, this separation force is balanced by diffusion in a polarised layer (induced by entropic diffusion or diffusion induced by surface interaction) or by friction in a deposit layer. As shown in next paragraph, force balances in a polarised layer or in a deposit can be described by the same equation when considering a solid pressure.

Mass transfer in a polarised layer: the balance between convection and diffusion

In a polarised layer at steady state, the balance between convection and diffusion for a fully retentive membrane leads to:

$$
J \phi-D(\phi) \frac{d \phi}{d x}=0
$$

Considering the Stokes-Einstein law [10] linking the diffusion coefficient to the osmotic pressure, $\pi(\phi)$, and to the hydrodynamic coefficient $K(\phi)$ :

$$
\frac{D(\phi)}{D_{b}} d \phi=K(\phi) d \pi^{*} \text { with } \pi^{*}=\pi \frac{V_{p}}{k_{B} T}
$$

Eq. 2 can also be written:

$$
\phi d x=\frac{D_{b}}{J} K(\phi) d \pi^{*}
$$


Mass transfer in a deposit: the balance between permeation and compression

The permeation in a deposit is described by Darcy law:

$$
J=-\frac{k}{\mu} \frac{d p}{d x}
$$

An approach considering the balance between the permeation drag force and the force due to the pressure loss in the deposit leads to the following relationship between the deposit permeability $k$ and the hydrodynamic coefficient $K(\phi)$ [12]:

$$
k=\frac{2 a^{2}}{9} \frac{K(\phi)}{\phi}
$$

Eq. 5 and 6, combined to the fact that in a deposit, the sum of the pressure and the compression pressure is constant [5] lead to:

$$
\phi d x=\frac{D_{b}}{J} K(\phi) d \pi^{*}
$$

This equation is similar to eq. 4 for mass transfer in the polarised layer when considering the equivalence between the osmotic pressure of particles diffusing in the liquid and the compression pressure of the deposit by the permeation of the liquid. This analogy is a basement for our model.

Accumulated solid volume and thickness layer at the membrane surface

Integration of equation 4 and 7 from the bulk, $\pi_{\mathrm{b}}$, to the membrane solid pressure, $\pi_{\mathrm{m}}$, allows to calculate the total accumulated solid volume (in $\mathrm{m}^{3}$ of deposit solid per membrane $\mathrm{m}^{2}$ ), $\mathrm{Vs}_{\mathrm{t}}$, and the total thickness of the accumulation layer, $\mathrm{e}_{\mathrm{st}}$ :

$$
\begin{aligned}
& V s_{t}=\frac{D_{b}}{J} \int_{\pi_{b}^{*}}^{\pi_{m}^{*}} K(\phi) d \pi^{*} \\
& e_{S_{t}}=\frac{D_{b}}{J} \int_{\pi_{b}^{*}}^{\pi_{m}^{*}} \frac{K(\phi)}{\phi} d \pi^{*}
\end{aligned}
$$

Using same equations, solid volume and thickness of polarised layer and deposit layer are deduced from partial integration from $\pi_{\mathrm{b}}$ to $\pi_{\text {crit }}$ and $\pi_{\text {crit }}$ to $\pi_{\mathrm{m}}$ respectively.

\section{Solvent transfer: the filtration law}

The classical filtration law links the permeate flux to the cake resistance:

$$
J=\frac{\Delta P-\pi_{i}}{\mu\left(R_{m}+R_{C}\right)}
$$

Where $\pi_{i}$, the osmotic pressure at the interface between the suspension and the solid (membrane or deposit) can be equal to the solid pressure $\pi_{m}$ if there is no deposit or to $\pi_{\text {crit }}$ in presence of a deposit.

Assuming that the sum of liquid pressure and solid pressure is constant though the deposit [5]:

$$
p_{i}+\pi_{i}=p_{m}+\pi_{m}
$$

and that the permeate flux through the deposit is:

$$
J=\frac{p_{i}-p_{m}}{\mu R_{C}}
$$

then it comes:

$$
\pi_{m}=\pi_{c r i t}+J \mu R_{C}
$$

Using eq. 13, eq. 10 can be written in a non-dimensional form:

$$
\frac{J}{J_{0}}=1-\frac{\pi_{m}^{*}}{A}
$$


with $\quad A=\frac{\Delta P V_{p}}{k T}$

where A represents the ratio of the separation energy per volume unit, $\Delta \mathrm{P}$, on the diffusion energy per volume unit, $\mathrm{kT} / \mathrm{V}_{\mathrm{p}}$.

\section{Transient description of dead-end filtration}

In dead end filtration, accumulated solid volume for a constant bulk volume fraction is given by:

$$
V s_{t}=\phi_{b} \int_{0}^{t} J S d t
$$

which when combined with eq.8 and 14 gives:

$$
\phi_{b} \int_{0}^{t} J S d t=\frac{D_{b}}{J} \int_{\pi_{b}^{*}}^{A\left(1-\frac{J}{J_{0}}\right)} K(\phi) d \pi^{*}
$$

This equation describes the evolution of permeate flux with time. The solid pressure at the membrane, $\pi_{\mathrm{m}}$, (eq.14), the cake resistance (if $\pi_{\mathrm{m}}$ is superior to $\pi_{\text {crit }}$ in eq. 13 ), the accumulated solid volume (eq. 8) and the thickness (eq. 9) of the polarised layer and of the deposit are also deduced as well as the volume fraction profiles within polarised layer and cake.

From this set of equation, a critical accumulated solid volume can also be calculated. This critical accumulated volume of particles within the polarised layer, already introduced in a preceding work [13], corresponds to the transition from a reversible to an irreversible mass accumulation:

$$
V s_{p \text { crit }}=\frac{D_{b}}{J} \int_{\pi_{b}^{*}}^{\pi_{\text {crit }}^{*}} K(\phi) d \pi^{*}
$$

\section{Analysis of simulated data}

Using data in Table 1 to illustrate the potentialities of the model for dead-end filtration of a colloidal suspension. As shown in figure 3, evolution of permeate flux with filtered volume $\mathrm{V}$ (per square meter of membrane area) follows a classical trend for dead-filtration (rapid decline) preceded by a short period where only a small reduction in permeate flux is observed. This corresponds to first period of filtration (accumulated solid volume less than $\mathrm{Vs}_{\mathrm{p} \text { crit }}$ ): only a small flux reduction is induced by osmotic pressure. Evolution of solid pressure and cake resistance at the membrane (fig. 4) shows how transition occurs from a polarised layer to a deposit during the filtration. It can be noted that pressure drop mainly occurs in the deposit layer. The same transition is illustrated when considering variations with distance to the membrane, as in figure 5. An important feature can be pointed out from concomitant variations of deposited volume and polarised volume versus liquid volume filtered (fig.6): the solid volume in the polarised layer increases with filtration time. This comes from the fact that when the permeation flux decreases, the critical volume in the polarised layer increases (eq. 19): when the drag force is reduced, the volume of particles in the polarised layer needed to compress the particles to overcome aggregation threshold raises. The solid volume fraction in the deposit is then smaller than expected from the total solid volume transfer. This has important consequences in the estimation of cake resistance from dead end filtration data. In figure 7, we compare results for cake resistance deduced from the slope using classical law of dead end filtration (with a graph $t / \mathrm{V}$ versus $\mathrm{V}$ ) and results obtained from this modelling. Its shows a difference of around $50 \%$ in the specific resistance value, as a direct consequence of a deposited volume being twice less than expected from 
solid volume flux towards the membrane. A corrected law for dead end filtration accounting for these phenomena would be proposed in a next publication.

\section{Conclusion}

This model is a first step to the description of the mass accumulation in a membrane filtration process including both polarisation, formation and compaction of a deposit. Two major parameters are used to describe colloidal suspensions properties within the polarised layer and the deposit: the solid pressure $\pi(\phi)$ and the hydrodynamic coefficient $K(\phi)$.

Modelling lies on two major points:

- The continuous description of colloidal properties versus volume fraction from the solid suspension in the liquid to the solid percolated by the liquid.

- The analogy in equation between the description of permeation in a deposit and the diffusion in a polarised layer.

Application to dead end filtration shows that accounting for colloidal properties, actual mass of particles irreversibly transfer to deposit can be very different from the mass transferred by permeation from the solution. This comes from the fact that when the permeation flux decreases, the critical volume in the polarised layer needed to compress the particles to overcome aggregation threshold increases. A direct consequence is a false estimation of specific resistance from dead end filtration data when assuming the mass of colloids in the deposit corresponds to solid volume flux towards the membrane. Other important consequences on reversible/ irreversible control of fouling in both dead end and tangential filtration are now under investigations.

\section{List of symbols}

A ratio for separation energy (eq. 15)

a particles or macromolecules radius; $\mathrm{L}$

D diffusion coefficient, $\mathrm{L}^{2} . \mathrm{T}^{-1}$

e accumulation layer thickness, $\mathrm{L}$

$\mathrm{J} \quad$ Mean permeate flux, $\mathrm{L} . \mathrm{T}^{-1}$

$\mathrm{K}$ Hydrodynamic coefficient

$\mathrm{k}$ deposit permeability, $\mathrm{L}^{2}$

$\mathrm{k}_{\mathrm{B}} \quad$ Boltzman constant, $\mathrm{M} \cdot \mathrm{L}^{2} \cdot \mathrm{T}^{-2} \cdot \mathrm{K}^{-1}$

$\mathrm{m}$ deposit compressibility

$\mathrm{P}$ pressure, $\mathrm{M} \cdot \mathrm{L}^{-1} \cdot \mathrm{T}^{-2}$

$\mathrm{R}$ hydraulic resistivity, $\mathrm{L}^{-1}$

S membrane surface, $\mathrm{L}^{2}$

$\mathrm{T}$ temperature, $\mathrm{K}$

$\mathrm{V}$ filtered volume per membrane area, $\mathrm{L}$

$\mathrm{V}_{\mathrm{s}}$ solid accumulated volume per membrane area, $\mathrm{L}$

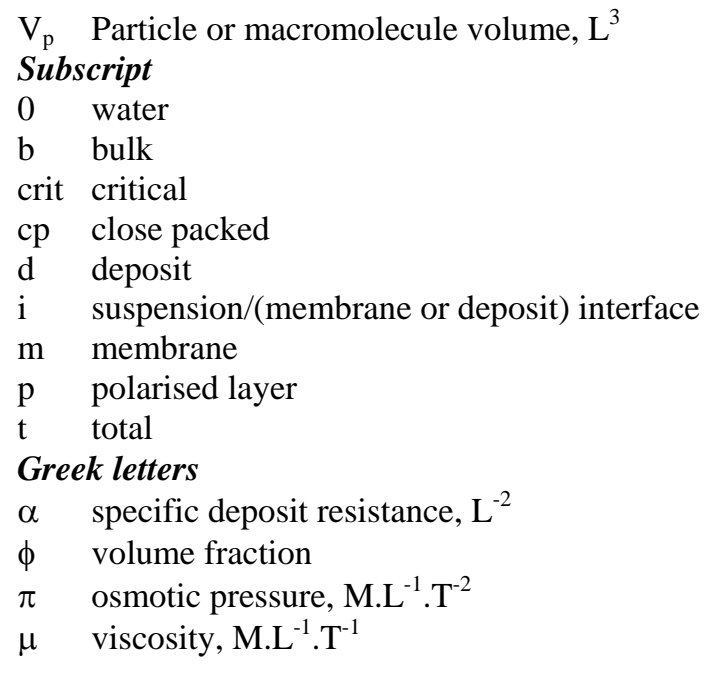

\section{$\underline{\text { References }}$}

[1] S. Bhattacharjee, A.S. Kim and M. Elimelech, Concentration polarisation of interacting solute particles in cross flow membrane filtration, J. Colloid Interface Science, 212 (1999) 81-99.

[2] P. Bacchin, P. Aimar and V. Sanchez, Model for colloidal fouling of membranes, AIChE J., 41 (1995) 368376.

[3] W.R. Bowen and P.M. Williams, Obtaining the osmotic pressure of electrostatically stabilised colloidal dispersions from frontal ultrafiltration experiments, J. Colloid Interface Science, 233 (2001) 159-163.

[4] R. Buscall and L.R. White, The consolidation of concentrated suspensions, J. Chem. Soc. Faraday Trans., 83 (1987) 873-891.

[5] J.D. Sherwood, Initial and final stages of compressible filtercake compaction, AIChE J., 43 (1997) 14881493.

[6] P. Bacchin, D. Si-Hassen, V. Starov, M.J. Clifton and P. Aimar, A unifying model for concentration polarization gel-layer formation and particle deposition in cross-flow membrane filtration of colloidal suspensions, Chem. Eng. Sci., 75 (2002) 77-91. 
[7] W.B. Russel, D.A. Saville and W.R. Schowalter, Colloidal dispersions, Cambridge Univ. Press, Cambridge, 1989.

[8] K.A. Landman and L.R. White, Determination of the hindered settling factor for flocculated suspensions, AIChE J., 38 (1992) 184-192.

[9] D.N.Petsev, V.M Starov and I.B. Ivanov, Concentrated dispersions of charged colloidal particles: sedimentation, ultrafiltration and diffusion, Colloids and Surfaces A, 81 (1993) 65-81.

[10] A.S. Jönsson and B. Jönsson, Ultrafiltration of colloidal dispersions - A theoretical model of the concentration polarization phenomena, J. Colloid Interface Sci., 180 (1996) 504-518

[11] A. Einstein, Investigation on the theory of the Brownian movement, ed. R. Furth, New York : Dover Publications, 1956.

[12] A.A. Zick and G.M. Homsy, Stokes flow through periodic arrays of spheres, Journal of fluid mechanics, 115 (1982) 13-26.

[13] P.Harmant and P. Aimar, Coagulation of colloids retained by porous wall, AIChE J., 42 (1996) 3523-3532. 
Table 1 : Common data set used for calculations.

\begin{tabular}{|c|c|c|c|c|c|}
\hline \multicolumn{2}{|c|}{ Suspended matter } & \multicolumn{2}{|c|}{ Aggregated matter } & \multicolumn{2}{|c|}{ Suspension medium } \\
\hline radius & $a=100 \mathrm{~nm}$ & Close packed & $\phi_{\mathrm{cp}}=0,7404$ & Ionic strength & $\mathrm{I}=10^{-4} \mathrm{M}$ \\
\hline zéta potential & $30 \mathrm{mV}$ & volume fraction & & Ion valence & 1 \\
\hline $\begin{array}{c}\text { Hamaker } \\
\text { constant }\end{array}$ & $10^{-20} \mathrm{~J}$ & Compressibility & $\mathrm{m}=1$ & viscosity & $\mu=10^{-3} \mathrm{~kg} /(\mathrm{m} . \mathrm{s})$ \\
\hline
\end{tabular}


Fig 1 : Phase diagram and phase transitions in a stable concentrated colloidal suspension.

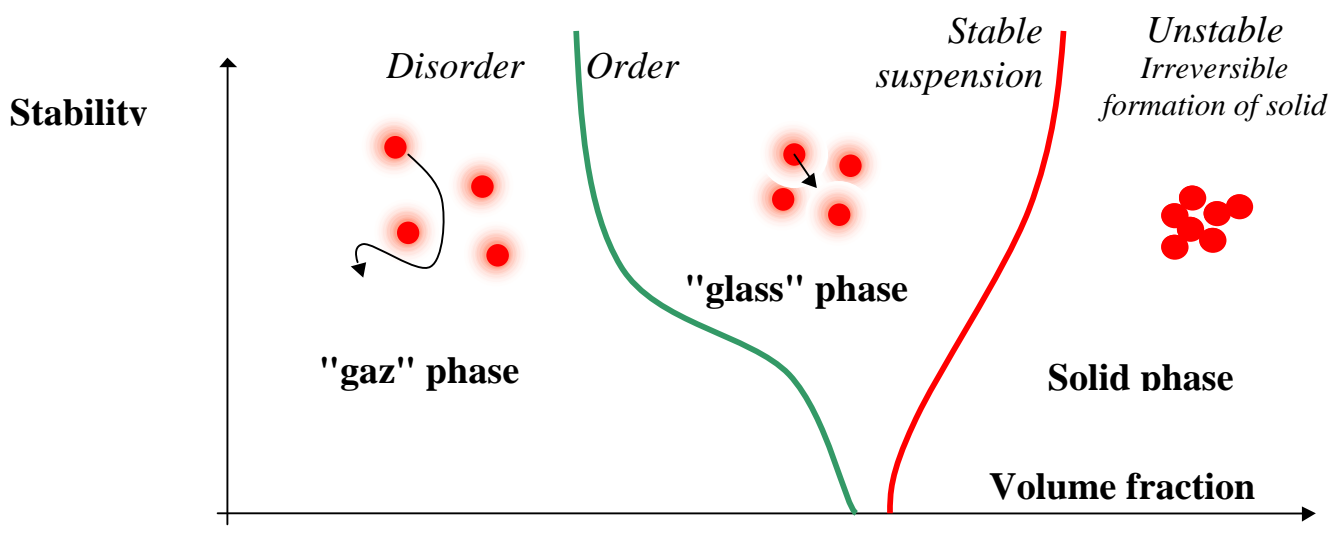


Figure 2 : Evolution of solid pressure as a function of volume fraction (Black square for osmotic pressure calculation, open circles for compressive pressure, dash line for osmotic pressure beyond spinodal decomposition )

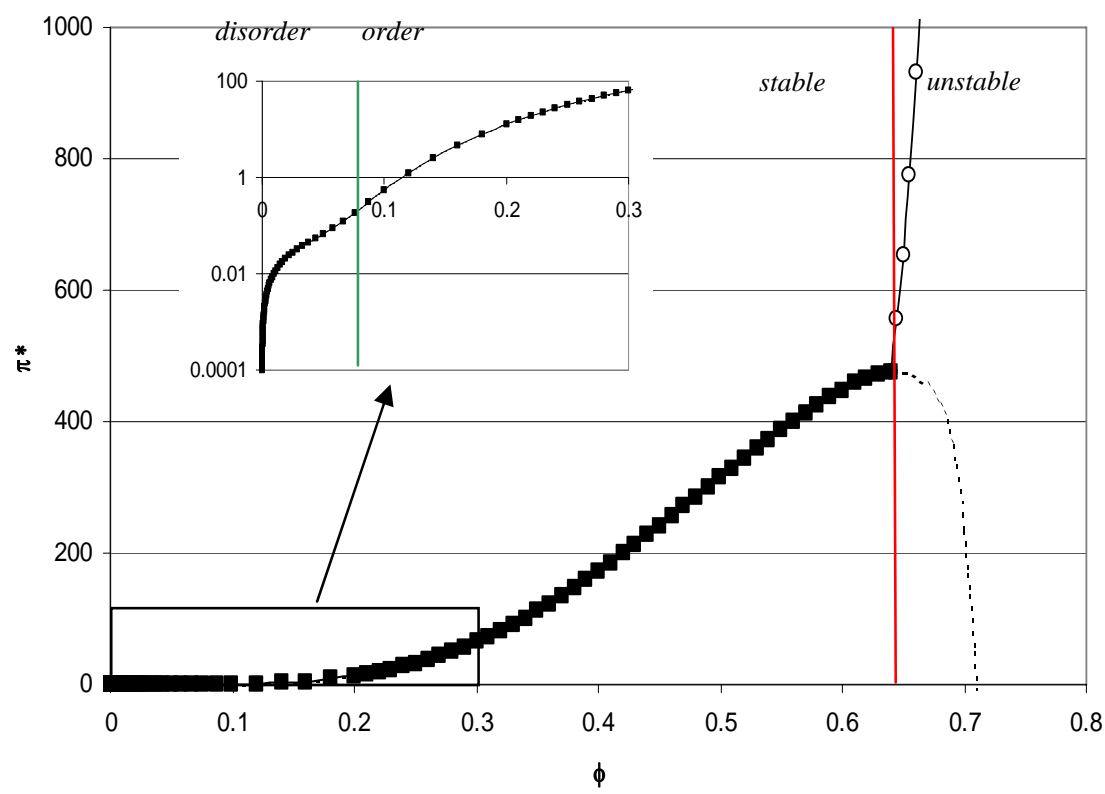


Figure 3 : Evolution of permeation flux versus filtered volume

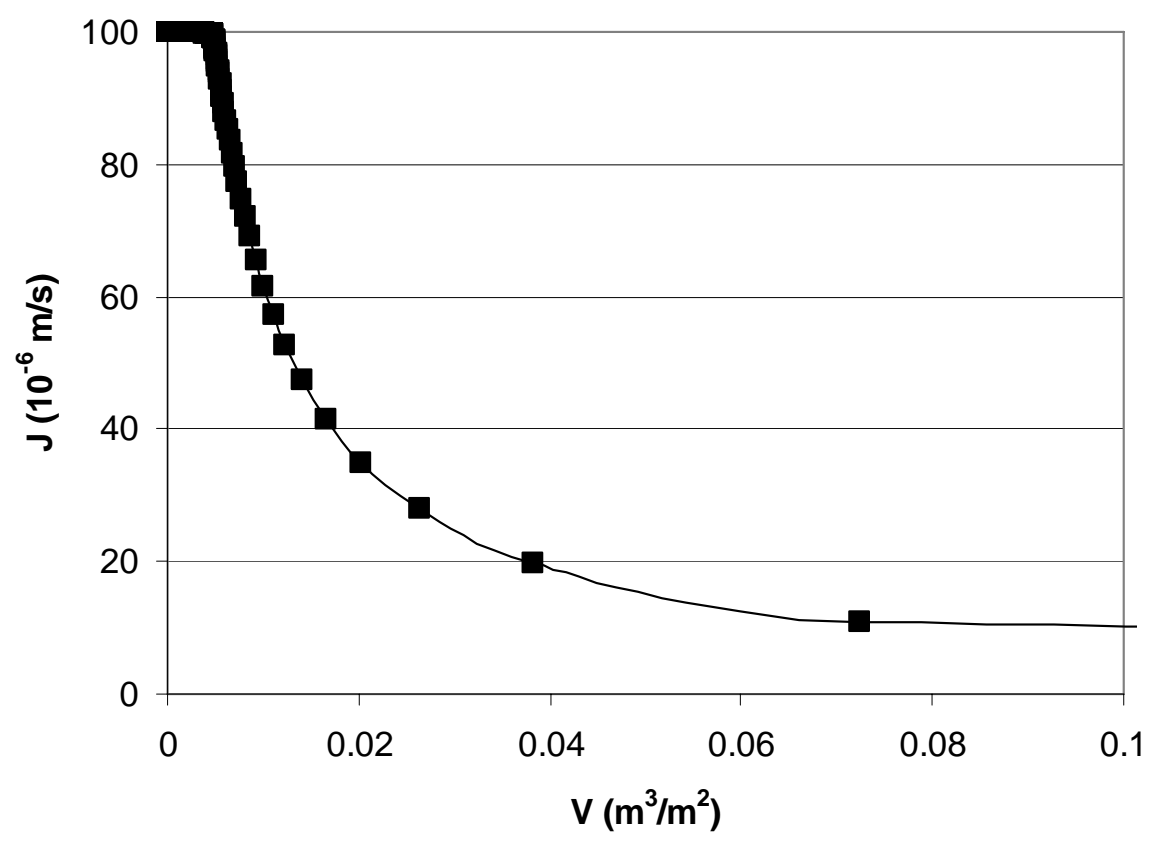


Figure 4 : Variation of the solid pressure at the membrane over transmembrane pressure and desposit resistance over membrane resistance versus filtered volume

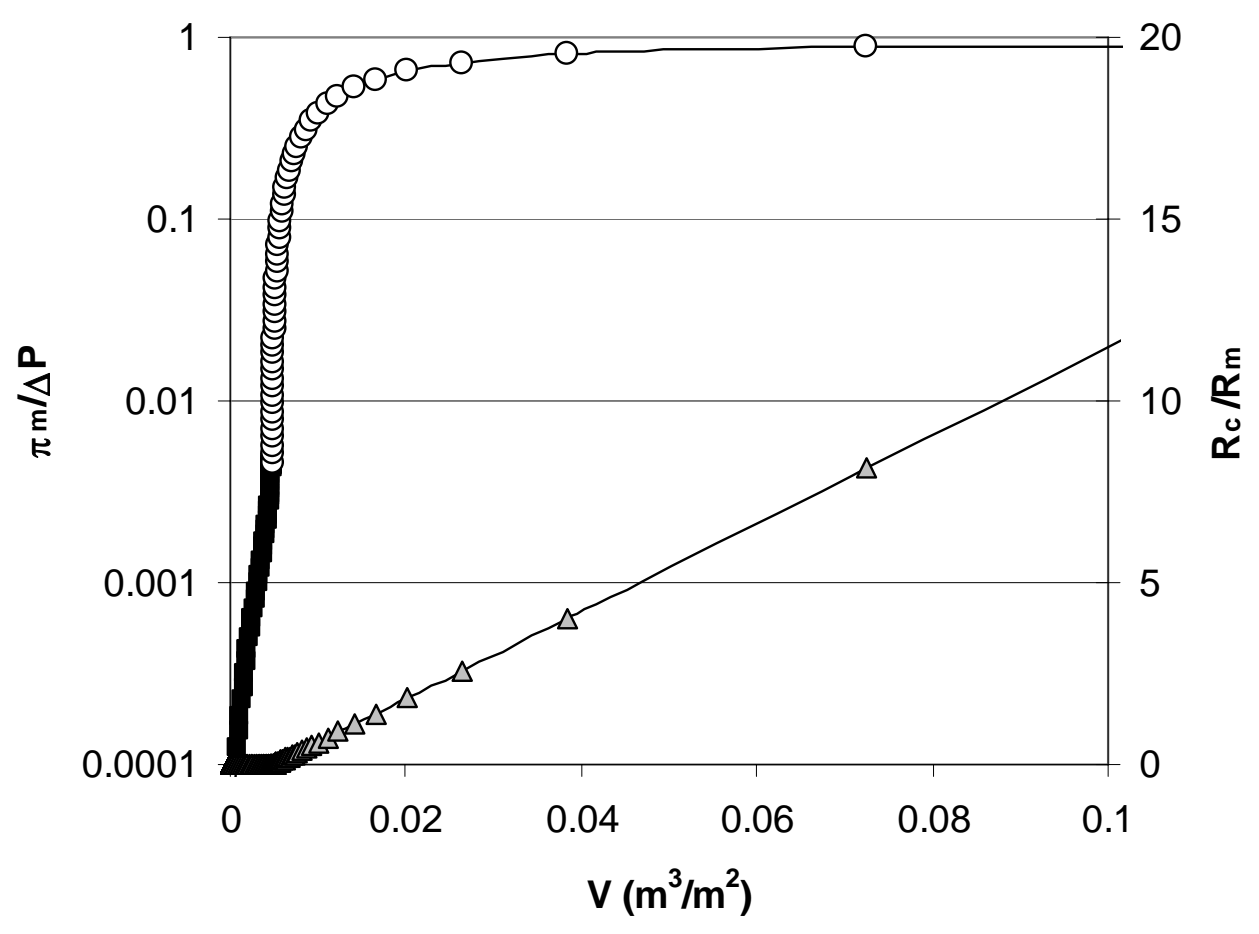


Figure 5 : Profile of volume fraction $\phi$ and pressure $P$ along the accumulated layer. $x$ is the distance to the membrane. Calculation is made for a filtered volume of $0,1 \mathrm{~m}^{3} / \mathrm{m}^{2}$.

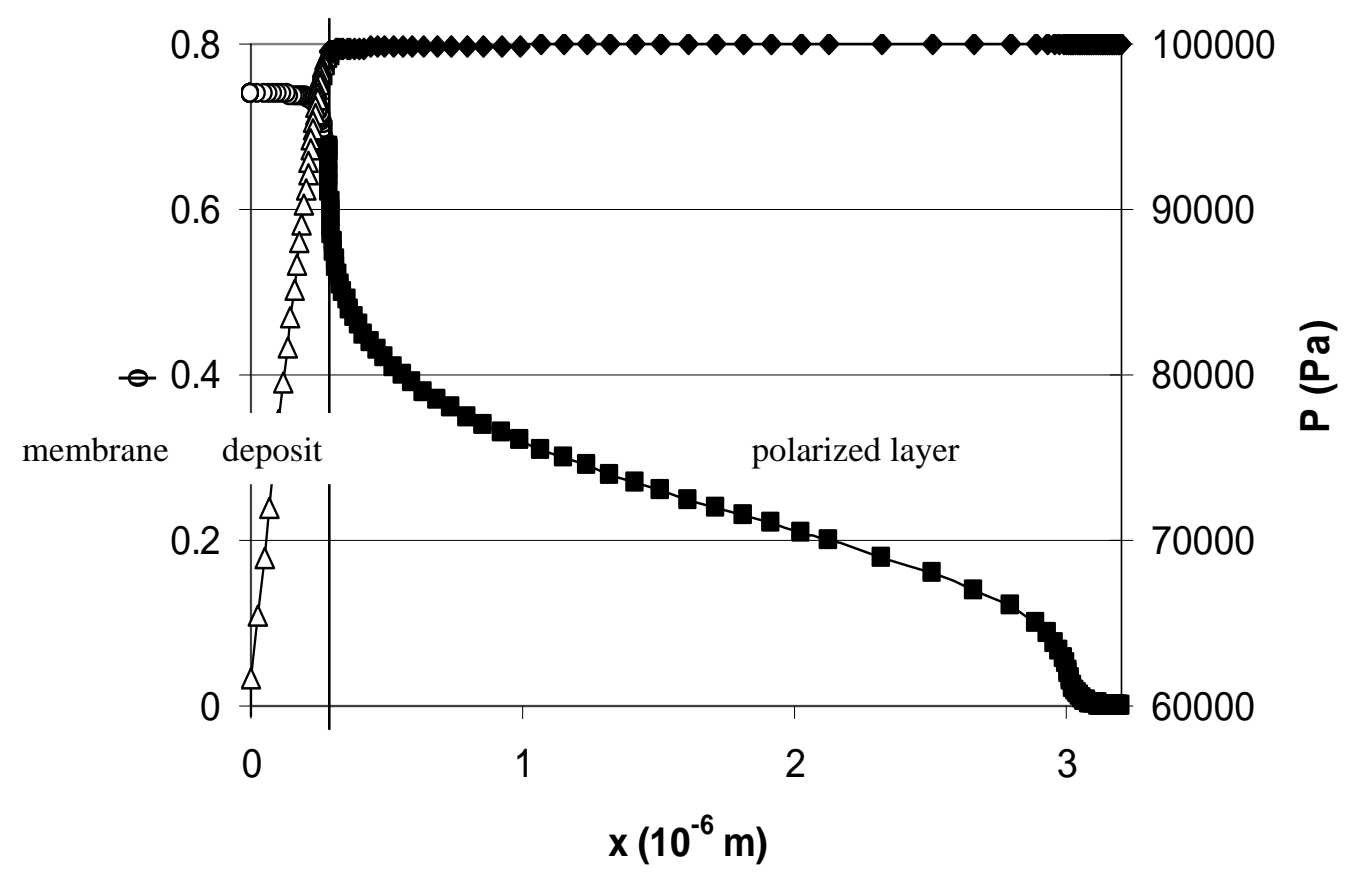


Figure 6 : Accumulated volume in the polarised layer $V s_{p}$ and in the deposit $V s_{d}$ versus filtered volume

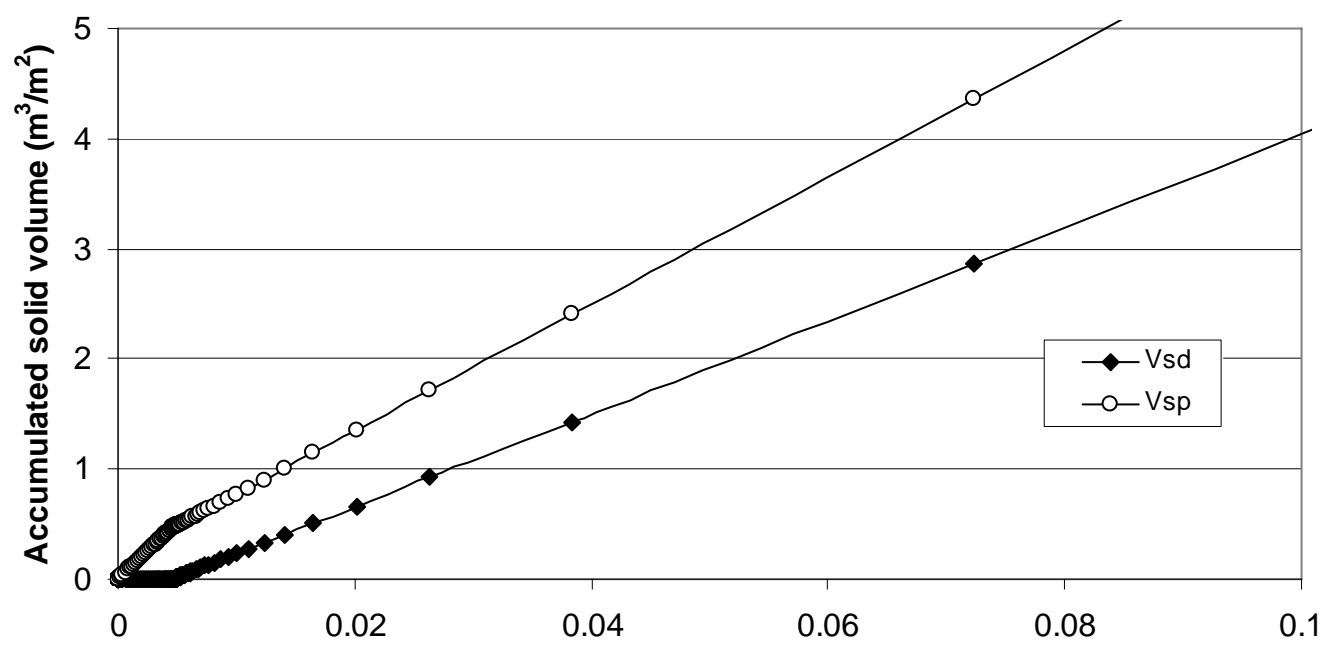

Filtered volume $\mathrm{V}\left(\mathrm{m}^{3} / \mathrm{m}^{2}\right)$ 
Fig. 7 : Calculation of deposit specific resistance a as a function of filtered volume from the modelling and from the classical method for dead end filtration with the slope of the line $t / V$ versus $V$.

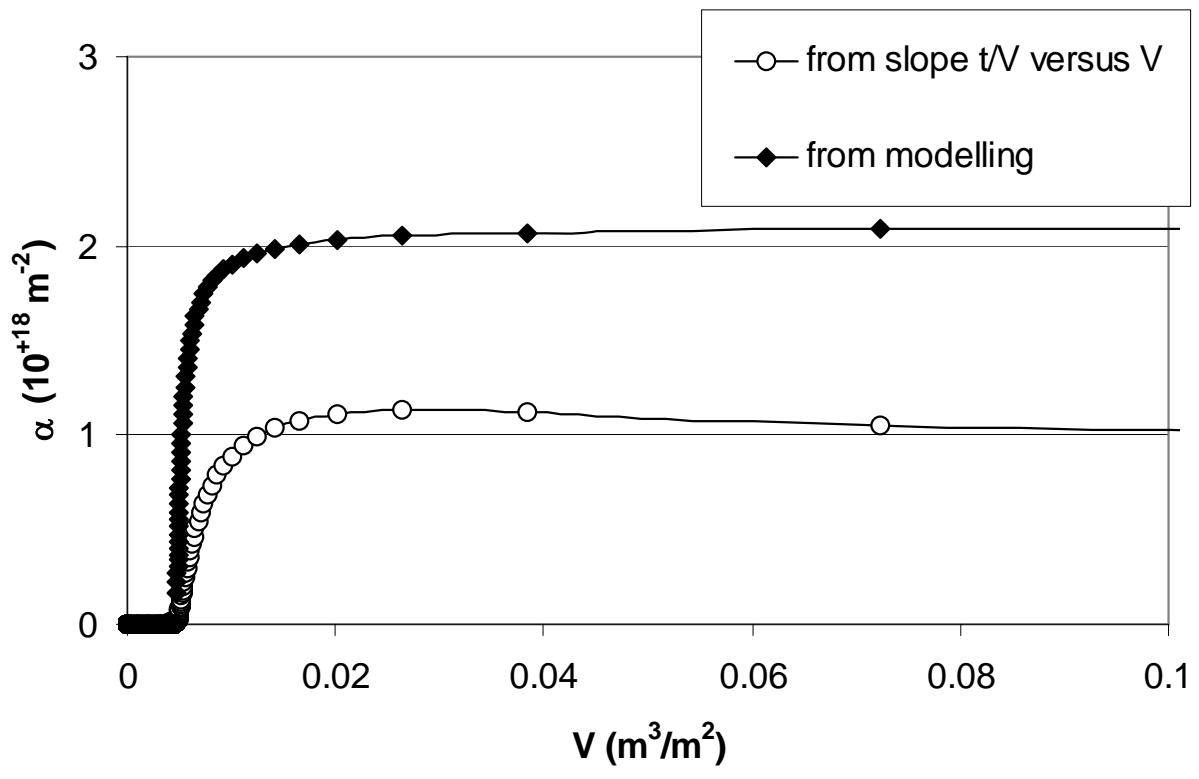

